This item was submitted to Loughborough's Research Repository by the author.

Items in Figshare are protected by copyright, with all rights reserved, unless otherwise indicated.

\title{
Analysis of SI combustion diagnostics methods using ion-current sensing techniques
}

PLEASE CITE THE PUBLISHED VERSION

http://www.sae.org/congress/2006/

PUBLISHER

(C) SAE International

VERSION

VoR (Version of Record)

LICENCE

CC BY-NC-ND 4.0

\section{REPOSITORY RECORD}

Panousakis, Dimitris, Andreas Gazis, Jill Patterson, and Rui Chen. 2011. "Analysis of SI Combustion Diagnostics Methods Using lon-current Sensing Techniques”. figshare. https://hdl.handle.net/2134/8407. 
This item was submitted to Loughborough's Institutional Repository (https://dspace.lboro.ac.uk/) by the author and is made available under the following Creative Commons Licence conditions.

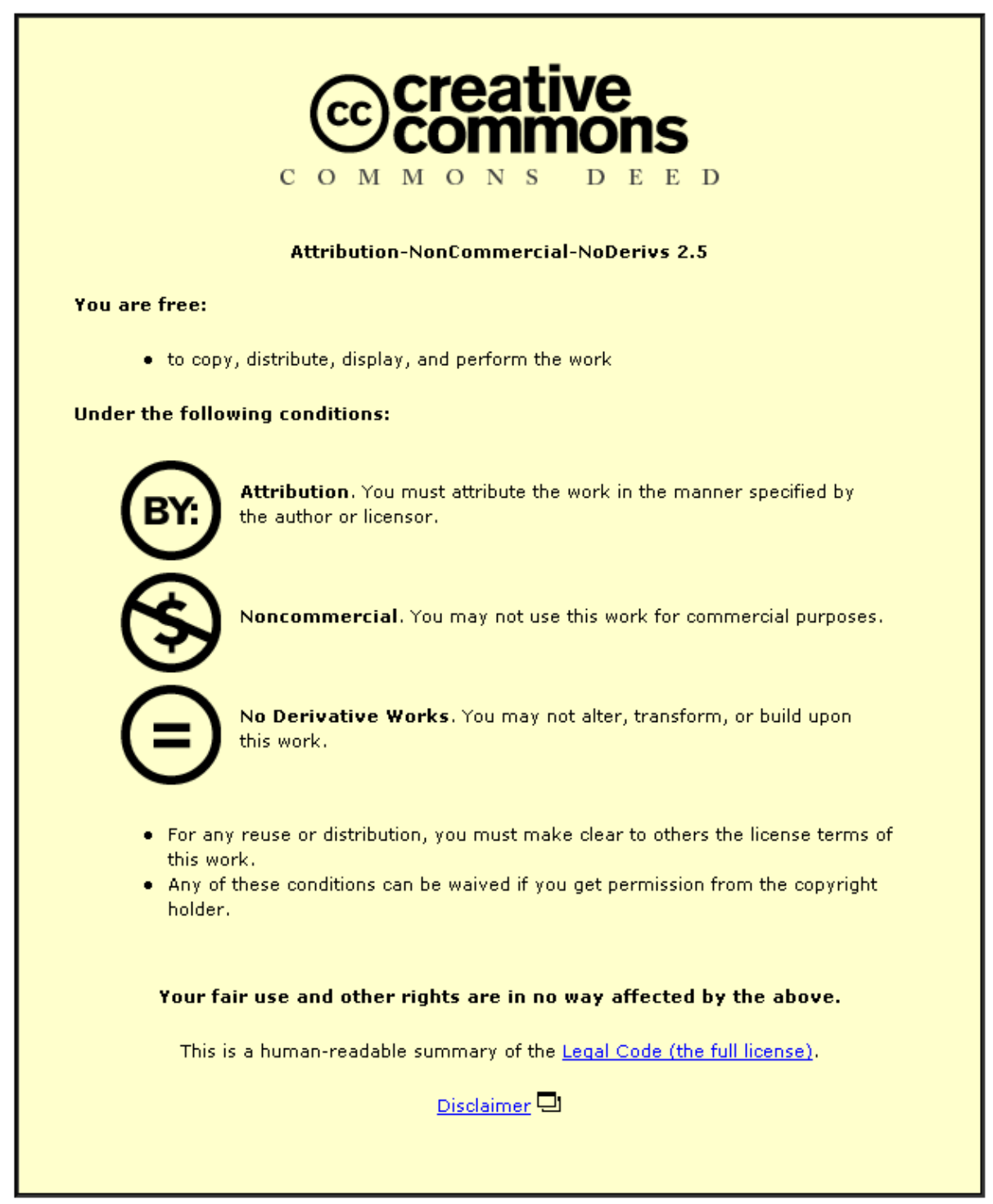

For the full text of this licence, please go to: http://creativecommons.org/licenses/by-nc-nd/2.5/ 


\section{Analysis of SI Combustion Diagnostics Methods Using lon-Current Sensing Techniques}

Dimitris Panousakis, Andreas Gazis, Jill Patterson and Rui Chen

Loughborough University

Reprinted From: Combustion and Flow Diagnostics and Fundamental Advances in Thermal Fluid Sciences 2006

(SP-2015)

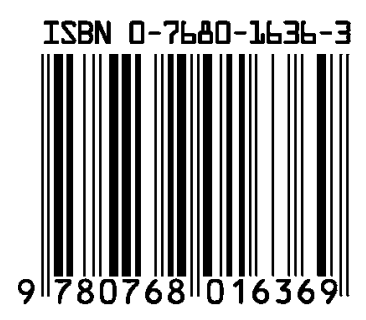


The Engineering Meetings Board has approved this paper for publication. It has successfully completed SAE's peer review process under the supervision of the session organizer. This process requires a minimum of three (3) reviews by industry experts.

All rights reserved. No part of this publication may be reproduced, stored in a retrieval system, or transmitted, in any form or by any means, electronic, mechanical, photocopying, recording, or otherwise, without the prior written permission of SAE.

For permission and licensing requests contact:

SAE Permissions
400 Commonwealth Drive
Warrendale, PA 15096-0001-USA
Email: permissions@ @ sae.org
Tel: $\quad 724-772-4028$
Fax: $\quad 724-776-3036$

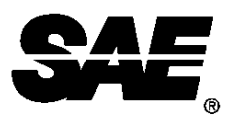

Global Mobility Database ${ }^{\circledR}$

All SAE papers, standards, and selected books are abstracted and indexed in the Global Mobility Database.

For multiple print copies contact:

\author{
SAE Customer Service \\ Tel: $\quad$ 877-606-7323 (inside USA and Canada) \\ Tel: $\quad$ 724-776-4970 (outside USA) \\ Fax: $\quad$ 724-776-0790 \\ Email: CustomerService@sae.org
}

\title{
ISSN 0148-7191
}

\section{Copyright $\odot 2006$ SAE International}

Positions and opinions advanced in this paper are those of the author(s) and not necessarily those of SAE. The author is solely responsible for the content of the paper. A process is available by which discussions will be printed with the paper if it is published in SAE Transactions.

Persons wishing to submit papers to be considered for presentation or publication by SAE should send the manuscript or a 300 word abstract to Secretary, Engineering Meetings Board, SAE.

\section{Printed in USA}




\title{
Analysis of SI Combustion Diagnostics Methods Using Ion-Current Sensing Techniques
}

\author{
Dimitris Panousakis, Andreas Gazis, Jill Patterson and Rui Chen \\ Loughborough University
}

Copyright $@ 2006$ SAE International

\begin{abstract}
Closed-loop electronic control is a proven and efficient way to optimize spark ignition engine performance and to control pollutant emissions. In-cylinder pressure sensors provide accurate information on the quality of combustion. The conductivity of combustion flames can alternatively be used as a measure of combustion quality through ioncurrent measurements. In this paper, combustion diagnostics through ion-current sensing are studied. A single cylinder research engine was used to investigate the effects of misfire, ignition timing, air to fuel ratio, compression ratio, speed and load on the ion-current signal. The ion-current signal was obtained via one, or both, of two additional, remote in-cylinder ion sensors (rather than by via the firing spark plug, as is usually the case). The ion-current signals obtained from a single remote sensor, and then the two remote sensors are compared.
\end{abstract}

lon-current signal interpretation was then conducted using an artificial neural network strategy (using adaptive linear networks) to interpret the measured signals, and also to predict the associated cylinder pressures. The combination of remote sensors with a linear neural network gives a more accurate and 'noise' free signal that can be processed at greater speed through computationally inexpensive methods.

The computed results agree well with measured cylinder pressures under all analyzed conditions. It will be shown that ion-current signals can be used to directly diagnose combustion abnormalities (and as such could suitable as part of a closed loop control strategy), even though the effects of ignition timing, air to fuel ratio, and compression ratio on ion-current were more complex.

\section{INTRODUCTION}

Electronic control with closed-loop feedback is a proven and efficient way to optimize the spark ignition (SI) engine performance and to control pollutant emissions [1]. Incylinder pressure sensors provide accurate information on the quality of combustion, but alternatively, so called 'ion- current' signals can be used to monitor in-cylinder combustion performance. The prevailing conditions inside the engine during combustion causes ionization of the gases in the cylinder. By applying a voltage (of the order of a hundred volts), a current will be produced since the ionized gasses are conducive.

The most obvious way to apply a voltage inside the cylinder is to use two existing electrodes; the spark plug tips [2], and a typical trace of data acquired by this method is shown in Figure 1, where the signal has been averaged over a number of engine cycles that were acquired with the firing plug. It is unlikely that such a well behaved trace would be encountered without averaging over several cycles with this method.

It can be seen in Figure 1 that the ion-current signal can be generally divided into three phases: the first phase consists of two sharp spikes located at 30 and 15 degree of crank angle (degCA) before top dead centre (BTDC). These are due to ignition and the measuring circuit rigging where the ion-current is measured most commonly from the low voltage side of the coil, and the emf interference causes some spikes to appear in the ion-current signal. This problem also occurs even when the less common practice of measuring from the high voltage side of the coil is employed.

After the first two spikes, the second phase of the ioncurrent signal appears as a first hump at around 10 degCA BTDC. This is a result of the flame kernel development around the tips of the spark plug. The level of the ioncurrent within this region is generally high due to intense chemical reactivity in the vicinity of the tips.

After the establishment of the combustion kernel, flame propagation towards the rest of the mixture starts. The intensified heat energy release from the burning "flame ball" growing in the cylinder warms the burned gasses inside it and further increases their temperature. As a result, the internal energy of the burned gasses increases and the ion formation rate becomes strong in comparison to the ion recombination rate [2]. Overall, after a short period of decline due to the flame front moving away from the sensor, the ion signal starts to rise again due to energy 
addition from the surrounding burning mixture. This gives the second hump in the signal, and the third phase of the ion-current signal. As the piston moves away further from TDC, the volume of the combustion chamber increases and in-cylinder pressure and temperature of the burned gasses decline. The ion recombination rate increases, and the measured ion-current signal starts to decline. This third phase of the ion-current signal is a post-flame or thermal ionization induced signal $[5,6,7,8,9,10]$, and it is proportional to the cylinder pressure produced by combustion.

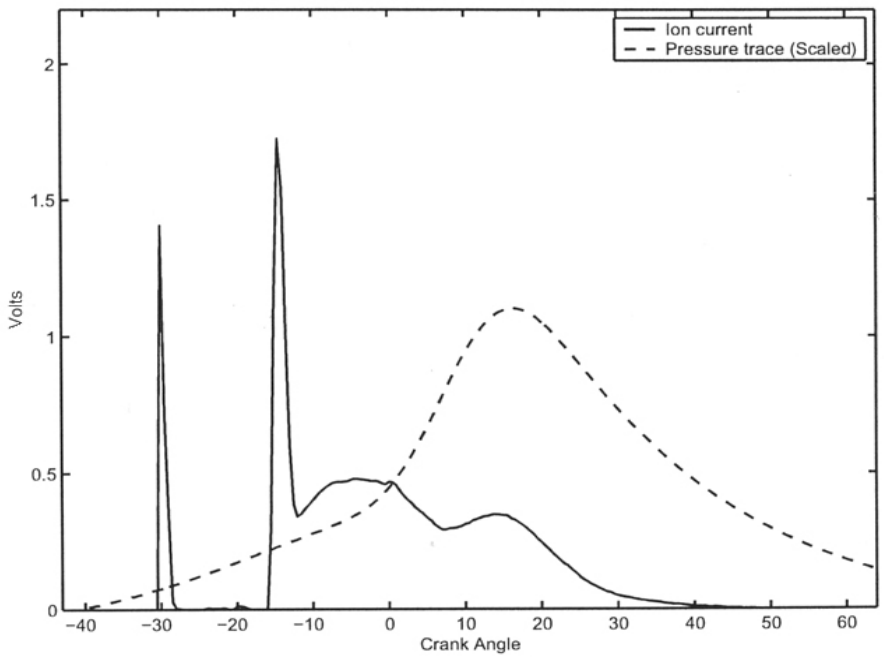

Figure 1 Typical ion-current signal (and pressure signal) recorded by a central plug [2]

There are some problems associated with using the spark plug as the ion-current sensor. Firstly, because the spark generating voltage is substantially higher than the typical voltages used in an ion-current measuring circuit, the latter has to be protected somehow, and no meaningful information can be gathered until the ignition circuit has dumped down thus the initial phase of combustion cannot be recorded. The best signal therefore derived from the thermal phase of the signal, but this second hump is not always very well pronounced thus making it a less than perfect feedback signal for engine diagnostic and control purposes. Moreover, cylinder pressures decrease as the engine load reduces, further reducing the signal strength of this second hump. Consequently, the diagnosable region of the engine loads are limited to a minimum of $75 \%$ of full load.

In this research, two ion-current sensors were used in addition to a single spark plug in order to avoid the weak signal experienced by using a combined spark plug and ion signal sensor. Here, the spark plug was used only as a combustion initiator, and the ion-current sensors were located on the opposite side of the combustion chamber. This configuration allows for the measurement of flame propagation speeds, since the timing of flame arrival at the sensors is possible.

\section{EXPERIMENTAL INVESTIGATION}

A single cylinder 4-stroke research engine was used, and full details are presented in Table 1. The engine featured variable compression ratio, variable ignition timing, variable air to fuel ratio and four access points in the cylinder head.

\begin{tabular}{|l|l|}
\hline Bore & $80 \mathrm{~mm}$ \\
\hline Stoke & $100 \mathrm{~mm}$ \\
\hline Inlet Valve Opening & 12degCA BTDC \\
\hline Inlet Valve Closing & 64degCA ABDC \\
\hline Exhaust Valve Opening & 64degCA BBDC \\
\hline Exhaust Valve Closing & $12 \mathrm{degCA}$ ATDC \\
\hline Compression Ratio & $4.5: 1-13: 1$ \\
\hline Ignition Timing & $\begin{array}{l}55 \mathrm{deg} C A \\
\text { 20dDC - }\end{array}$ \\
\hline
\end{tabular}

Table 1. Engine Specification

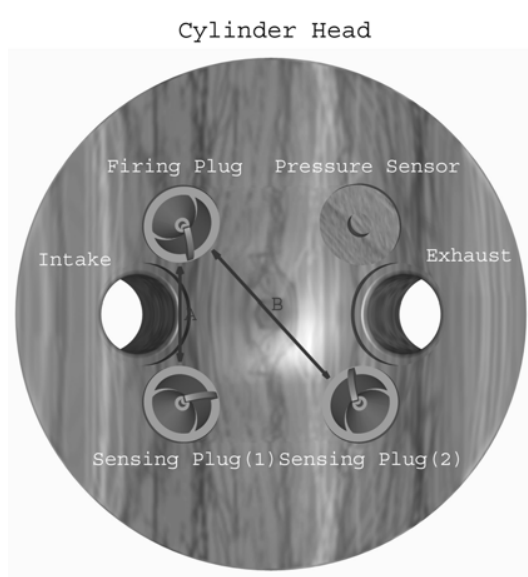

Figure 2 Cylinder head fitted with 1 spark plug and two remote ion sensors

Figure 2 shows the arrangement of the cylinder head and the spark plug locations. The firing plug, which is located next to the inlet valve was used as the ignition source while one, or both, of the two remote sensing plugs were used as the ion-current sensing units. One was fitted on the other side of the inlet valve opposite to the firing plug (sensing plug (1) in the diagram) whilst the other, (sensing plug (2)), was fitted next to the engine exhaust valve. The distance between sensing plug (1) and the firing plug was $42 \mathrm{~mm}$, and the distance between the sensing plug (2) and the firing plug was $55 \mathrm{~mm}$.

Since the mass of positive ions, such as $\mathrm{H}_{3} \mathrm{O}^{+}$, is approximately 30,000 times larger than that of an electron (negative), the light electrons can be accelerated much more easily towards the positive electrode than the heavy ions when driven by an applied electromagnetic field [1]. The voltage polarity at the gap of sensing spark plugs was therefore selected so that the small area electrode, the centre electrode, was positive, and the large area electrode and the rest of the combustion chamber were negative. This coincides conveniently with the spark plug's 
original polarity as it is used in most engines where the engine block is negative.

A purpose built DC voltage source, (shown in figure 3), was used to power the measuring plugs. The output of the voltage divider was passed to a data acquisition (DAQ) board as the ion-current signal. The voltage divider would produce a voltage that was inversely proportional to the sensed ion-current (i.e. $5 \mathrm{~V}$ for zero ion-current and $\mathrm{OV}$ for infinite) to avoid the possibility of damage caused due to excessive voltage. The signal was inverted during the post processing phase. The DAQ sampling rate was one sample per 2 degCA. Data were acquired using either a single sensing plug (1) or both. When using both sensing plugs, these were connected in parallel, as shown in Figure 3 , which essentially results in the addition of the two ion-current signals.

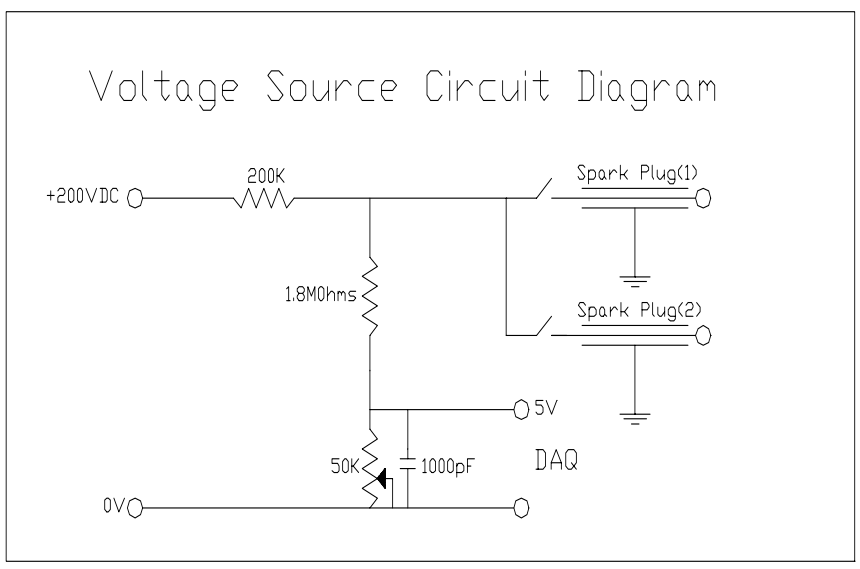

Figure 3 Circuit Diagram of DC Source

All experiments were conducted first using the single remote ion-current sensor, and then repeated with both remote sensors to asses the extent by which additional sensors improve the quality of ion-current data.

When the flame front passes the sensing plug, the gas around the plug is burned. The balance between the ionization and recombination of the burned gas constituents is then a function of temperature and pressure. This leads to a post-flame hump similar to that recorded when the firing plug is also used for measurement.

\section{EXPERIMENTAL RESULTS WITH REMOTE ION SENSING PLUG(S)}

The ion-current signal was initially measured using a single remote sensor, namely sensing plug (1). Figure 4 shows a typical measured cylinder pressure and a correlated ioncurrent, taken from a selected single cycle, rather than from an average of cycles, so that the phase transitions are clearly shown. By comparing Figure 4 with the results obtained from the firing spark plug shown in Figure 1, it can be seen that there is a significant difference between the two ion-current signals. One sharp spike instead of two is recorded during the first phase when a remote sensor is used, because there is no interference from the ignition circuit. The remote sensing plug detects the flame front as ion-current, caused by ionization within the gap of its electrodes, yielding this single sharp spike. Additionally, as the flame needs a certain time to propagate through the distance between the two plugs, the use of a separate sensor allows for this time to be measured as the delay between spark timing and the ion-current spike.

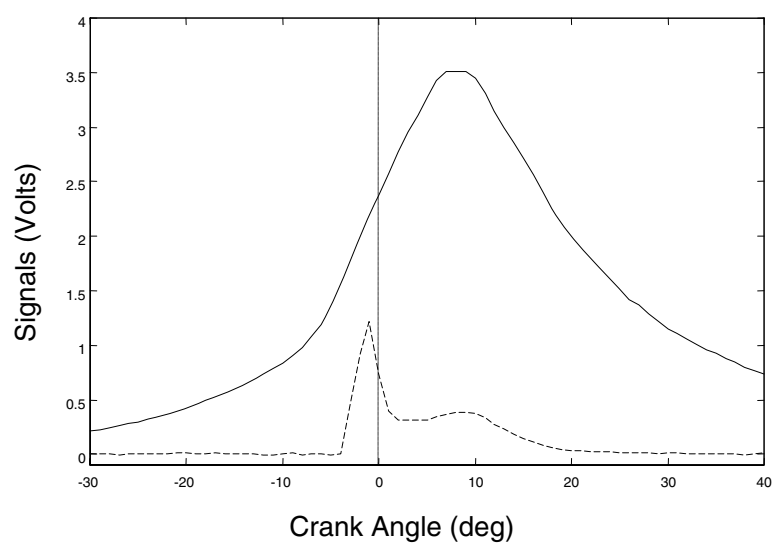

Figure 4 Single Plug lon-current and Pressure Signals

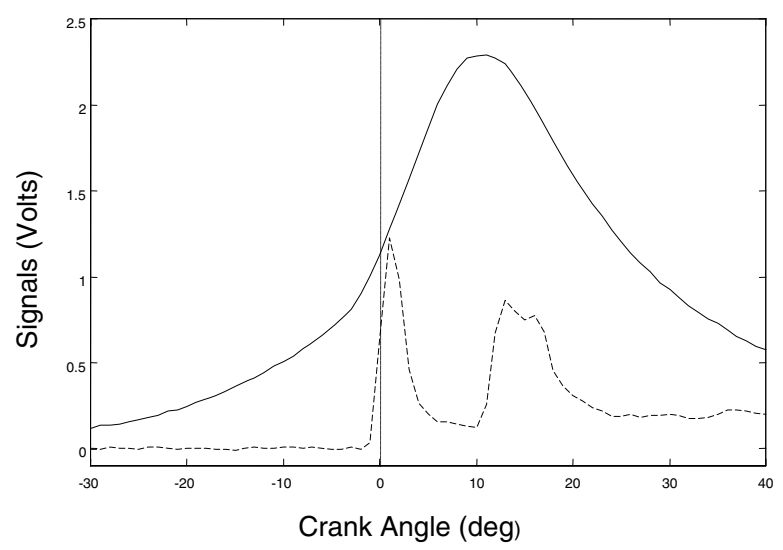

Figure 5 Twin Plug lon-current and Pressure Signals

The output from the twin remote sensors is combined, to give one signal, and it can be seen in Figure 5 that this results in additional information in the form of an additional spike between the original spike and hump. This is the result of the chemi-ionization ion-current signal produced as the flame front hits the second sensor's electrodes. The post flame hump here is the result of the pressure rise after the flame has passed both sensors and thus contains less information.

Comparison of figures 4 and 5 show that whilst most of the combustion information can be obtained from the spikes, the use of two sensors gives a greater insight into the combustion process, and provides a wider diagnostic window because the signal strength of second hump is increased. The drawback is that the use of the two additional sensors does not leave a time window for the 
post-flame information to be collected. The use of a single additional sensor provides a great improvement over using the spark plug as the only sensor where the weaker signals and lower slopes lead to unstable and inconsistent data, however the use of an ion-current sensor separate to the spark plug can potentially represent a significant increase in cost and complexity, and additionally difficulty to manufacturers.

The results also show that the location of the additional sensor is important. Assuming that a flame ball is generated by ignition, if the ion-current sensor is located symmetrically with the spark plug, the same result will be recorded. Alternatively, ion-current sensors can be embedded in the cylinder heat gasket, to overcome sealing and manufacturing problems, and represent the lowest cost approach to installation of ion current sensors. However, in terms of location, the use of remote ioncurrent sensors also represent an improvement cylinder head gasket sensors [26], because they cannot be used to analyze the first ion-current spike and provide no post flame data. Thus, in order to achieve the widest possible diagnostic window, it is better to locate a sensor between the ignition site and the flame out site. These effects are described further in the following section.

\section{RESULTS AND ANALYSIS}

\section{MISFIRE}

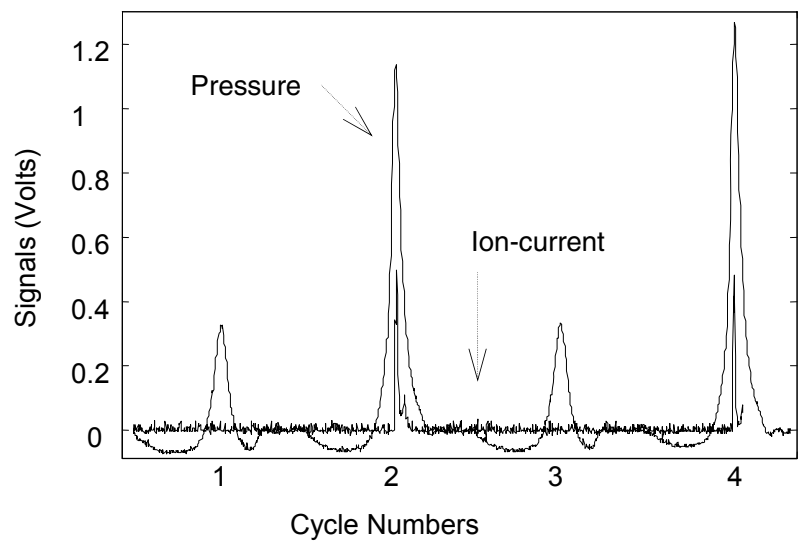

Figure 6 The misfire effect on ion-current recorded by a single remote sensing plug

Misfire detection is a major subject of on board diagnostics (OBD). Conventional crankshaft speed fluctuation sensing does not guarantee misfire detection at high engine speeds and low load conditions. This method is particularly poor for multi-cylinder engines where the effect of misfire of a single cylinder on crank shaft speed is masked by the frequent and successful combustion events of the other cylinders. The potential of ion-current sensing for misfire detection has already been reported $[11,12,13,14]$, and this study confirms that when misfire occurs the ion-current signal and its integral are zero, while under any other combustion condition they are non-zero.
This is demonstrated in Figure 6 where cycles 1 and 3 are misfired. Although, the signal shown here was obtained using one remote sensing plug, identical behavior was evident with two remote sensing plugs.

\section{IGNITION TIMING}

The effect of the ignition-timing on both pressure and ioncurrent can be seen in Figure 7. Advanced timing results in higher in-cylinder pressures and earlier first spikes of the ion-current signals since the flame propagates earlier. The flame starts earlier but also travels faster due to the increased pressure buildup. Again the number of sensors used is not critical in this application, since most information is given by the location of the starting point of the signal. The only advantage of recording of the location of two spikes from both sensors is increased signal strength. It is worth noting that the results in figure 7 are taken from a single cycle as opposed to an average of cycles, and the position of peak ion-current signal, and indeed peak cylinder pressure are not solely functions of ignition timing, but also of ignition delay. As such the spacing between pressure and ion-current peaks are not necessarily the same as the spark advance, but if this correlation is sought it can be improved by using averaged data.

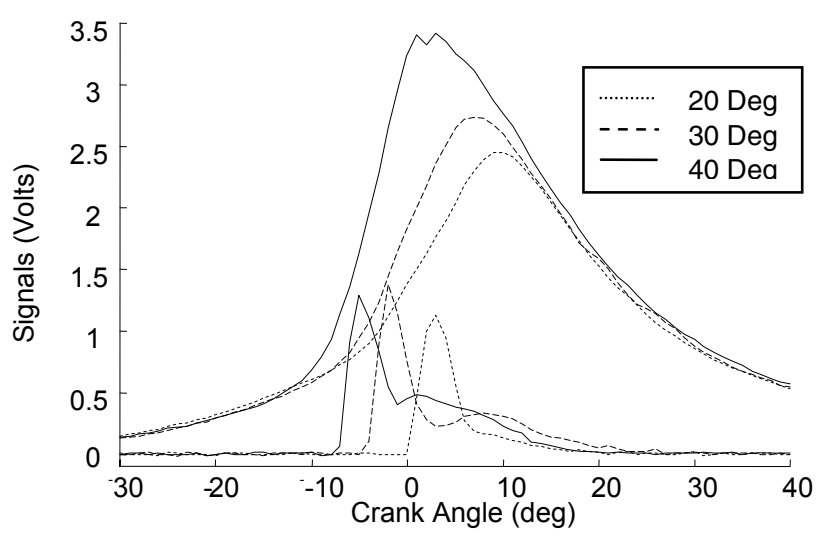

Figure 7 Ignition Timing Advance Effect on ion-current at $1500 \mathrm{rpm}, 50 \%$ throttle, $50 \%$ load and lambda= 0.9 from single cycles

\section{AIR TO FUEL RATIO}

In the plots shown in Figures 8 and 9, a comparison between the pressure and the ion-current signal under different AFR values is shown using data that was averaged over ten cycles using a single sensing plug. It can be seen that there is a very good correlation between pressure and ion-current at each air-fuel ratio, and the ioncurrent signal remained measurable at all AFR conditions.

In Figure 8 , the AFR was swept from a value of $\lambda=0.65$ to 1 at half load while the engine speed was held constant at $1600 \mathrm{rpm}$ and the ITA was $30 \mathrm{deg}$. In Figure 9, the AFR was swept from $\lambda=1$ to 1.26 under the same engine conditions. 

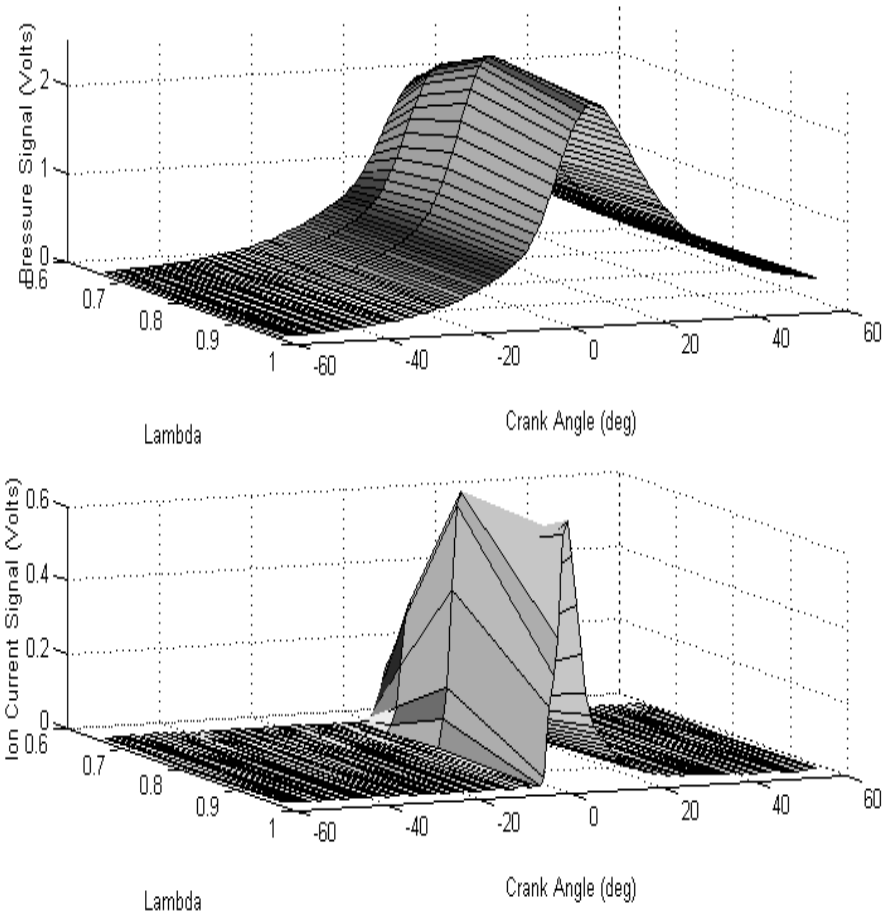

Figure 8 AFR swept from rich to stoichiometric at half load and $1600 \mathrm{rpm}$
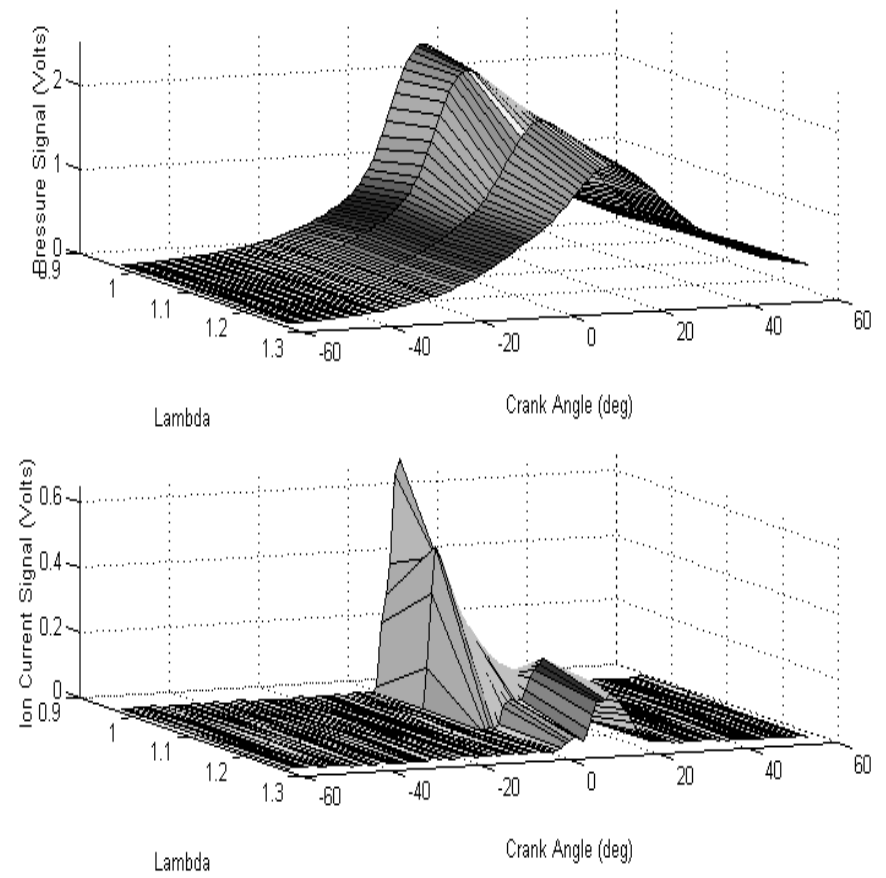

Figure 9 AFR swept from stoichiometric to lean at half load and $1600 \mathrm{rpm}$

The location of start of ion-current signal and peak ioncurrent position are interdependent with the pressure signal slope and location of peak pressure, and all of these parameters are a function of flame propagation speed. Where mixtures burn fast (at AFR's that are slightly lean of stoichiometric), the positions of the start and peak ioncurrent occur earlier, but very lean (and hence slow burning) mixtures have the greatest delays.

The magnitudes of the ion-current signals also correlate with the magnitudes of pressure signals. The mildly rich mixtures produce the highest values for ion-current and pressure signals. The signal strength decreases at both richer and leaner AFR's. For very lean mixtures, as with any low in-cylinder pressure condition, the post-flame phase disappears. What looks like a second hump on the signal from the leanest mixtures is in fact very late combustion.

Previous research has identified that the behavior of the first slope of the ion-current signal is an indicator of mixture strength [14], and this is confirmed by the results in Figure 10 where the AFR is plotted against the first ion-current slope. Each of the seven slope values is an average over sixty cycles under the same AFR conditions. The trend is for the ion-current signal to peak near to a stoichiometric AFR and decrease for richer or leaner mixtures. Further research is required to establish whether the ion-current sensor could replace an oxygen sensor, but it is clear that the ion-current signal can provide feedback for individual cylinder fuel trims in order to equalize cylinder air/fuel imbalances. The impact that such a strategy will have on the efficiency and emissions of production vehicles is considerable.

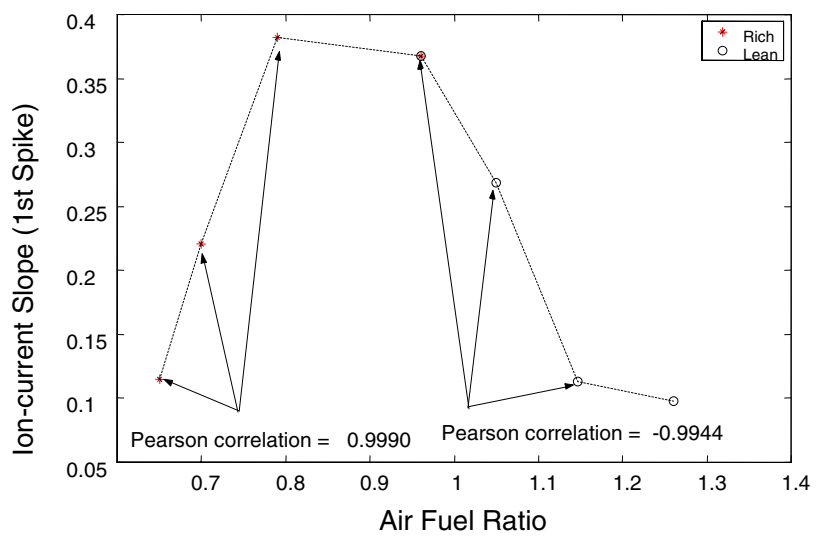

Figure 10 Relationship between the slope of the first loncurrent spike and Air-Fuel Ratio

\section{COMPRESSION RATIO}

Two sensors were used to acquire the data shown in Figure 11. The engine was run at half load and $1650 \mathrm{rpm}$, with the ITA at $30 \mathrm{deg}$ BTDC and an air fuel ratio of $\lambda=0.95$. Figure 11 shows plots of the in-cylinder pressure and ion-current signal for different compression ratios. As the compression ratio drops reducing the flame propagation speed, the start of the ion-current signal is delayed, and the peak pressure is also reduced and retarded. 
It is important to note that the engine was rebuilt between each test in order to vary the compression ratio. The reduced compression ratio would have affected the engine's thermodynamic efficiency, but this was not compensated for in the experiments.

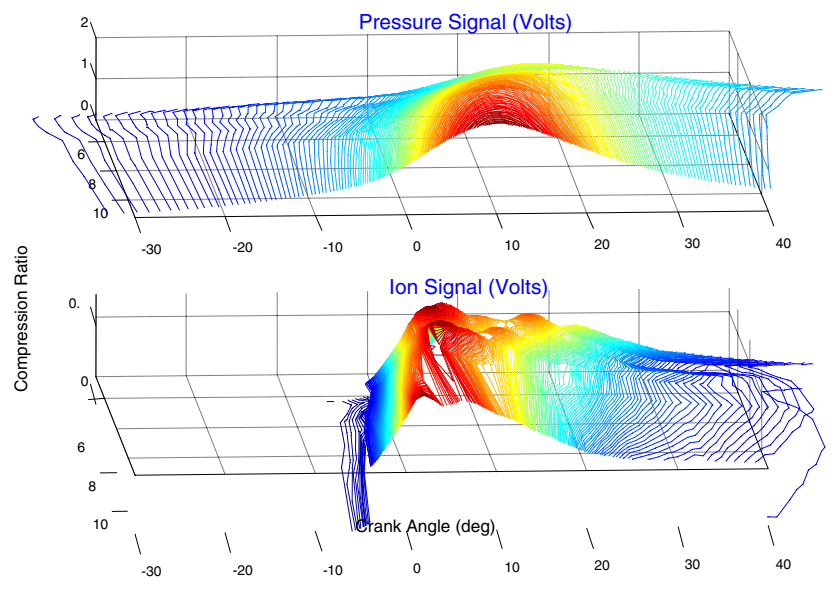

Figure 11 - Compression Ratio Effect

\section{LOAD / SPEED}

For the load/speed data collection the load was swept from $0 \%$ to $100 \%$ and the speed from 1000 to $3000 \mathrm{rpm}$. The air to fuel ratio was held at 0.9 lambda, and figure 12 shows the results recorded by using both ion-current sensors. Figure 12 shows that as the load increases the pressure increases and the peak cylinder pressure occurs earlier. The ion-current signal also increases and the maximum point appears earlier, but only up to about $75 \%$ load. After this point the ion-current signal continues to occur earlier but starts to fall in magnitude.
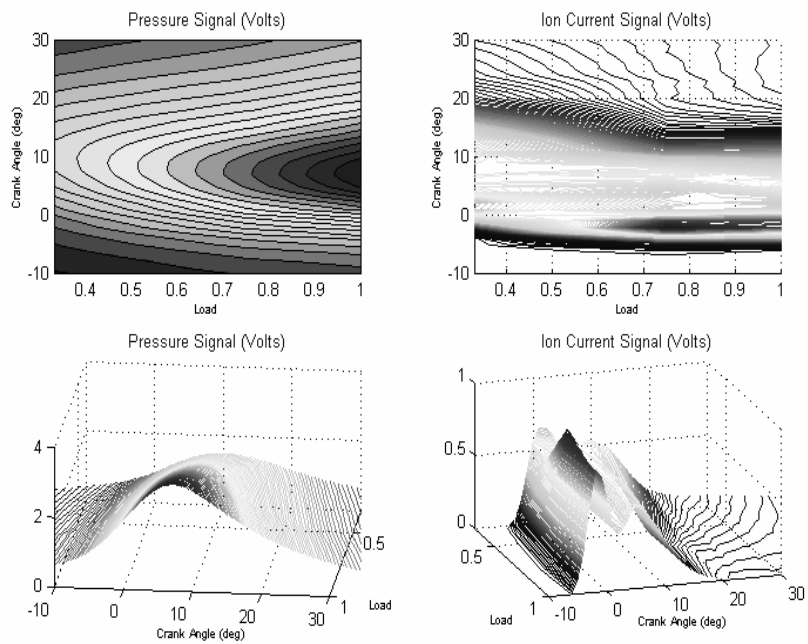

Figure 12 Load contour graphs

This effect was also observed with a singe ion-current sensor, and no easy explanation for this phenomenon is available since the ion formation process is not yet fully understood.

\section{TRANSIENT OPERATION PERFORMANCE}

The pressure and ion-current signals recorded during acceleration are shown in Figure 13, where the engine was accelerated from $1000 \mathrm{rpm}$ to $4000 \mathrm{rpm}$ at full load. A log obtained during deceleration is shown in Figure 15. The engine was decelerated from $4000 \mathrm{rpm}$ to idle speed at three quarters load.

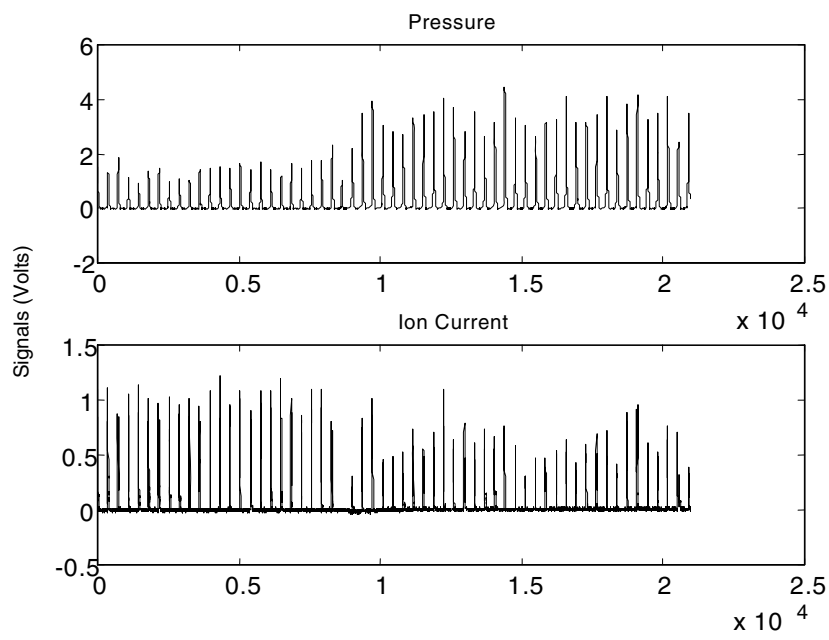

Figure 13 - Pressure and ion-current signals recorded as the engine was accelerated from $1000 \mathrm{rpm}$ to $4000 \mathrm{rpm}$ at full load.

In the data logs of Figure 13, the engine was kept at idle until the $0.8 \times 10^{4}$ data point, and then the throttle was suddenly fully opened. It is particularly interesting to note here that although the pressure increases after that point, the ion-current drops. This is largely due to the mixture leaning out momentarily at the sudden opening of the throttle, but it may also partly be due to the effect noted in the load/speed section where the magnitude of the ioncurrent signal drops above three quarters load. It can also be seen that misfire occurs at the point where the throttle is opened. This is due to fuel condensation in the inlet manifold and to inability of the carburetor to sustain stoichiometry during transients.

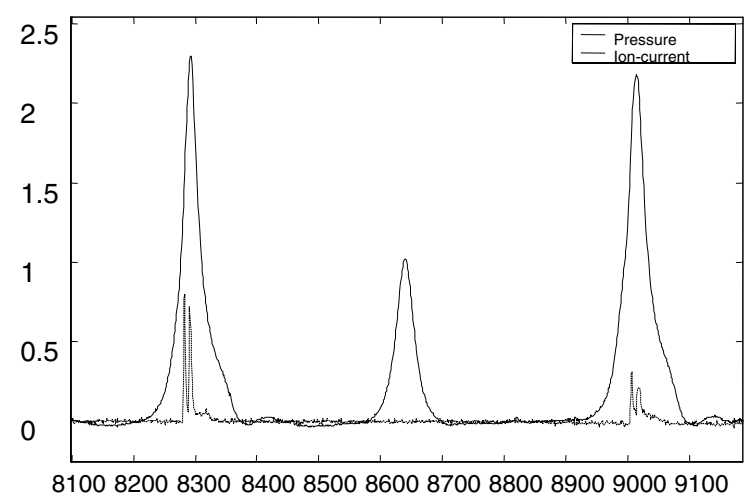

Figure 14 - Acceleration Misfire Detail from Figure 13. 
Figure 14 is an enlargement of data taken from Figure 13 over the cycles where misfire occurs. It can be seen that the ion-current signal is absent on the misfired cycle and weak on the cycle occurring directly after the misfire.
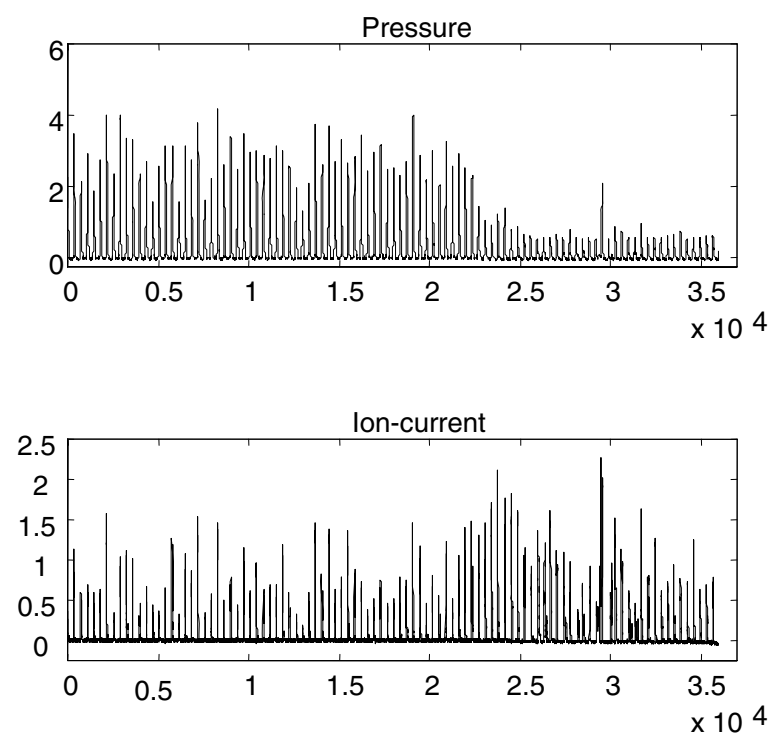

Figure 15 - Pressure and ion-current signals recorded as the engine was decelerated from $4000 \mathrm{rpm}$ to $1000 \mathrm{rpm}$ at three quarters load.

The behavior of the ion-current signal is exactly the opposite of the behavior shown during acceleration. Again, misfired cycles occur as the throttle is shut off due to momentarily over-rich air-fuel mixtures. Figure 15 also illustrates that the correlation between ion-current and cylinder pressure is very close in the $\mathrm{x}$ direction, but is much more complex in the $y$ direction as during transient performance, as the cylinder pressure decreases, ioncurrent actually increases. This may be partially understood by examining Figure 16, where it can be seen that the mixture actually ignites after the exhaust valve is opened.

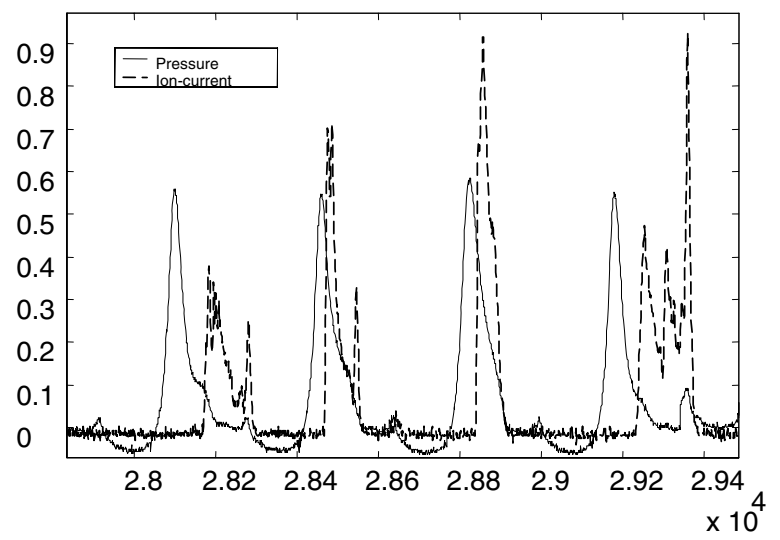

Figure 16 - A detail of the deceleration log showing misfired cycles where the mixture ignited at EVO.

\section{STATISTICAL ANALYSIS}

Preliminary understanding of the combustion attributes can be achieved by examining the signal characteristics as described above. In order to be able to extract more detailed information, some post-processing of the signal is needed. In this section a brief description of how the signals were analyzed and the portions of the signals that were used to extract useful information is given.

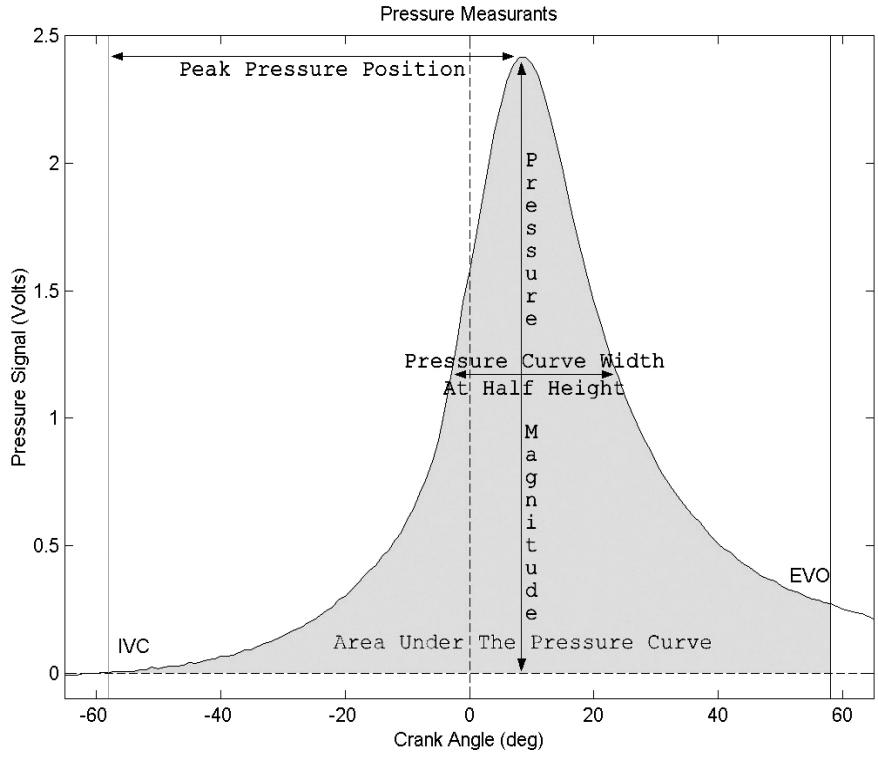

Figure 17. - Diagram of relevant pressure signal measurants.

For the curve integration, the start and endpoints are taken at the point where the inlet valve closes (IVC) and the exhaust valve opens (EVO) respectively. For the given engine, IVC was 116 degrees before the combustion TDC and EVO 116 degrees after it. Hence, the areas of the pressure curves quoted in this report are all between these two points.

The pressure measurants, as shown in Figure 17, with their names and their units are:

1. The position of the signal peak - measured in CA degrees after IVC

2. The magnitude of the signal peak - measured in signal Volts

3 The width of the curve at half its height - measured in CA degrees

4 The area under the curve - measured in CA degrees by signal Volts

For the ion-current signal curve integration, the start point is taken as the point where the signal rises above noise levels, while the end point is taken as the point where the signal drops to noise levels. If the ion-current signal is still 
strong at EVO, then this is taken as the end point since any combustion after EVO will not have a considerable effect on the pressure.

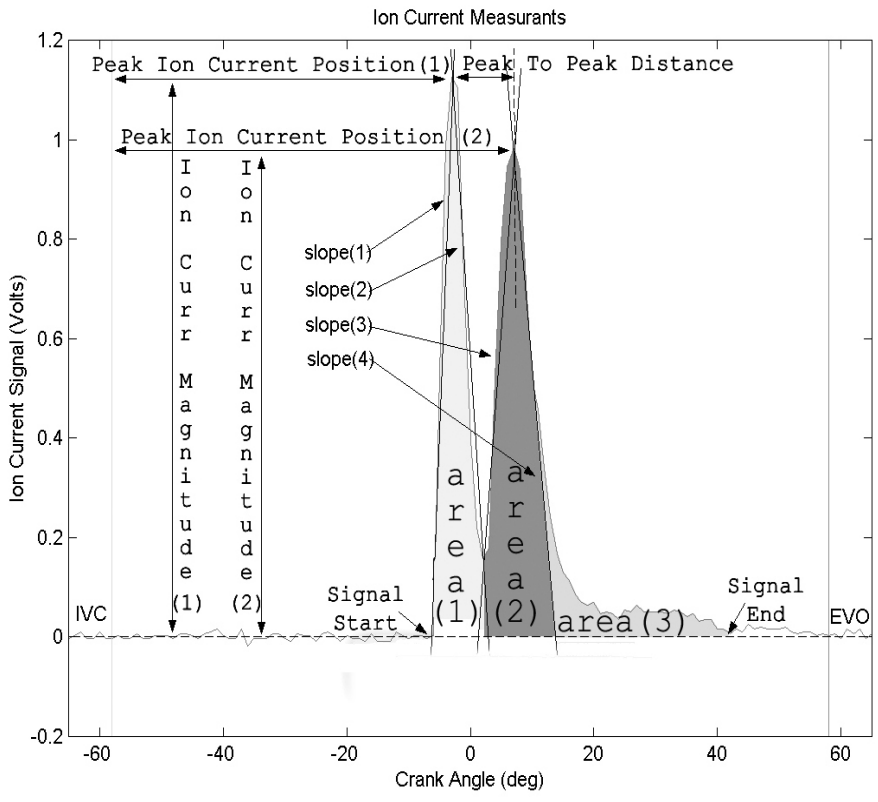

Figure 18 - Diagram displaying ion-current signal measurants

The most useful ion-current signal measurants (shown in Figure 18) are:

1 The position of the first point of a signal - measured in CA degrees after IVC, and the difference between the two peaks

2 The positions of the first and second spike peaks - CA degrees after IVC

3 The magnitude of both spikes - Volts

4 The three areas under the different regions of the signal - CA degrees $x$ Volts

5 The four slopes of the spikes - Volts / CA degrees

\section{DATA MANIPULATION}

In order to further analyze the ion-current data via artificial neural networks, the pressure measurants must be related to those of the ion-current, and so graphs of all possible combinations of the 4 pressure measurants were plotted against the 13 ion-current measurants described above.

The important trends, in terms of pressure ion-current correlation are common under all engine parameter changes. The results shown here, obtained by varying the ignition timing, are representative of all tested conditions. Results obtained by varying the compression ratio, load/rpm, air-fuel ratio and generally parameters that affect flame propagation speed, exhibit the same behavior, and thus the results from the other tests are omitted.

To find the best matches, a Pearson correlation test was carried out on the data. This is a statistical method the measure how well a linear equation describes the relation between two variables that are measured on the same object. It is defined as the sum of the products of the standard scores of the two measures, divided by the degrees of freedom. A score of 1 or -1 shows that the data lies on a line, where as a score of zero shows there is no linear relationship between the variables.

The data that were subject to this analysis were not averaged and the following graphs present the results on a cycle to cycle basis. The engine was run at $1600 \mathrm{rpm}$, half load, an air fuel ratio of 0.9 and the ignition timing advance for was swept from 55 to 50 to 40 to 20 and finally to 0 deg. Figure 19 shows correlation between the position of the first peak of the ion-current signal against the area under the pressure curve, and the Pearson correlation coefficient was -0.96588 showing an inversely proportional and almost linear relationship exists.

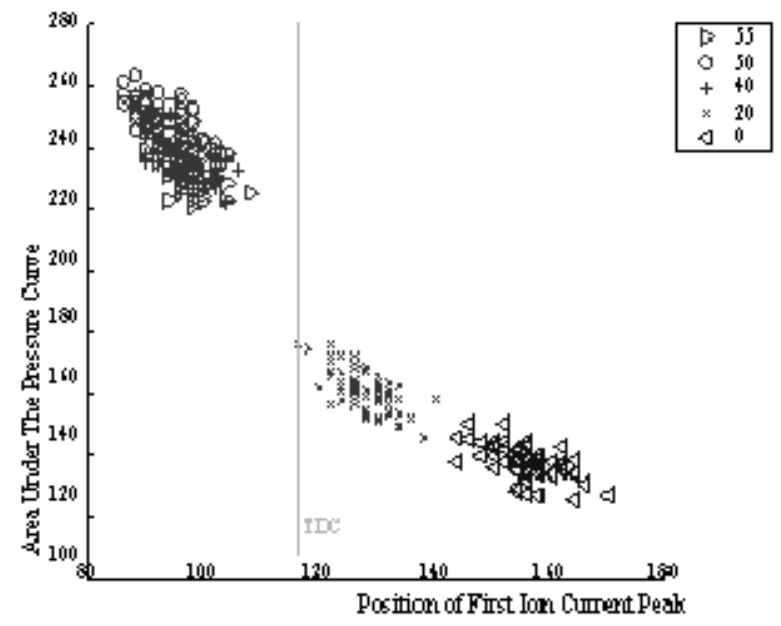

Figure 19 - Area under the pressure curve against the position of first peak of ion-current signal

The area under the pressure curve is linked to peak pressure magnitude, (the higher pressure results in a larger area under the curve). Both of these measurants are closely related to the position of the first peak of the ioncurrent. The same inversely proportional relationship exists for position of the first peak of the ion-current against pressure magnitude, and the Pearson correlation was 0.98016 .

The position of peak pressure is plotted against the peak of the first ion-current spike in Figure 20, and gives a Pearson correlation coefficient of 0.97866 . Again, this demonstrates a near linear relationship except this time the two measurants are directly proportional. This very good correlation was expected as the earlier the peak position occurs the earlier the flame reaches our sensor. 
Similar correlations were found between the position of the start of the ion signal and peak pressure position, yielding a Pearson coefficient of 0.97540 . The early start of the ioncurrent signal means early flame propagation, which equates to early peak pressure position.

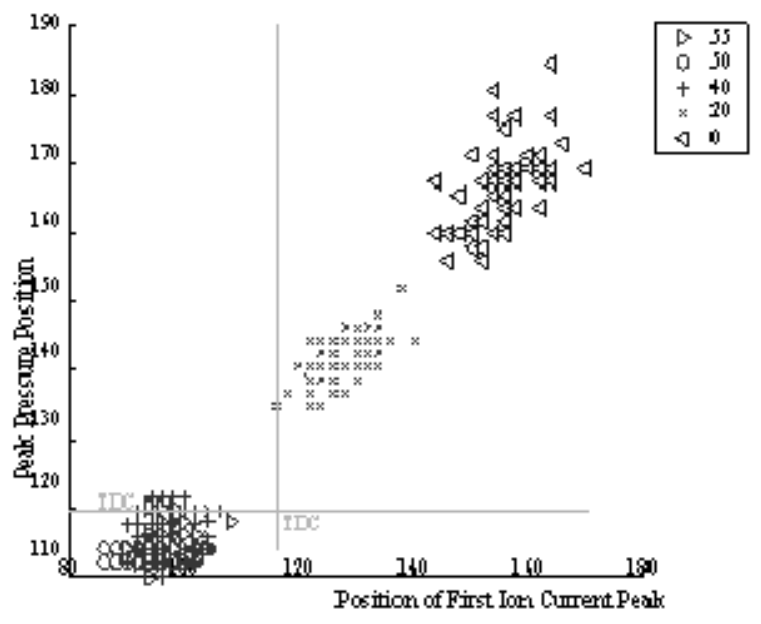

Figure 20 - Peak Pressure Position against the position of peak of the first ion-current spike

If the mixture was trimmed to higher dilution levels, a delay in the start and the peak of the spike of the ion signal would be noted. However, the slower flame speed would also affect the slope of the signal thus increasing the delay in-between these two points. So, since most of the characteristics are interrelated, it is not surprising that similar, although less striking trends were found when comparing most of signals' measurants.

\section{ARTIFICIAL NEURAL NETWORK MODEL}

The correlations mentioned above do not lend themselves to an analytic solution. No single correlation is strong enough to provide direct and robust pressure estimation while simplistic prediction algorithms will probably not meet the requirements if more than one parameters change simultaneously.

However, Artificial Neural Networks (ANNs), (which are known to be efficient in dealing with noisy and incomplete data) are a good candidate for tackling this kind of problem. These are fast computational constructs loosely modeled on real neural networks where each artificial neuron is a node that takes a number of inputs which are weighted and summed. Then the weighted sum is passed through a transfer function to give the final output. Their role is to summarize the inputs of the neuron into a value.

There are several network families to choose from when designing an ANN, but in the present study ADALINEs (ADAptive LInear NEtworks) [23] were used. In the past, perceptrons have been used for position of peak pressure estimation through ion-current sensing $[17,18,19]$. Like the perceptrons, ADALINEs are among the classic networks used extensively in various industrial applications. Their basic feature is that their transfer functions are pure lines $(y=x)$. One advantage of using them is that their inputs and outputs do not need any scaling in order to be used. Another advantage is that, if the input/output sets are known from the start, an ADALINE can always be designed with minimized error for these sets without need of iterative training techniques.

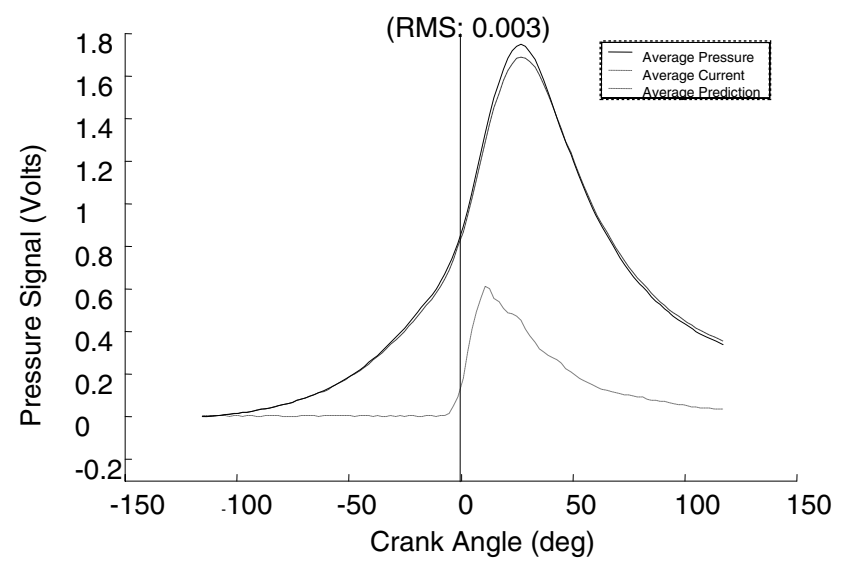

Figure 21 - The average actual pressure and ion-current signals, with the predicted pressure in dotted line

The nets were fed the signals of the logged files, the ioncurrent signal as an input set and the pressure signal as an output set. In addition, the engine conditions (throttle position, lambda value, rpm, ignition timing advance, compression ratio) were also supplied in log files of 70 consecutive engine cycles. The ADALINE was trained on a small number of these ( 5 to 15 logs) and was then tested on a hold out data set that had not been previously supplied to the network, and that had different parameter setting than had been used before. On the following plots, the performance of the ADALINE is demonstrated. All results shown are cycle-to-cycle predictions, apart from the average pressure curve reconstruction in Figure 21.

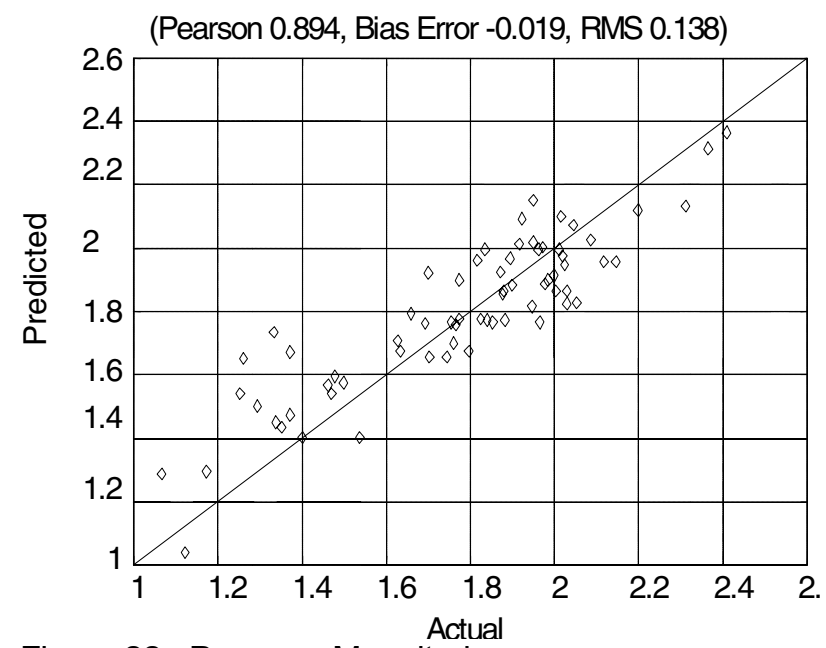

Figure 22- Pressure Magnitude

For the data presented here, the ADALINE was trained using logs under, mainly, varying compression ratio, while 
logs with varying load and speed were also used. The test file has a speed, load and compression ratio combination that the net has never seen before. As can be seen from the average pressure prediction over the 70 cycles is in good agreement with the actual average pressure shown , with a point-to-point RMS error of just 0.003 Volts.

The pressure magnitude prediction shown in Figure 22, exhibits an RMS error of 0.138 and a Bias error of -0.019 Volts, or $8 \%$ and $-1 \%$, respectively. The position of peak pressure prediction of Figure 23 has an RMS error of around 3 CA degrees and a Bias error of around $-0.5 \mathrm{CA}$ degrees.

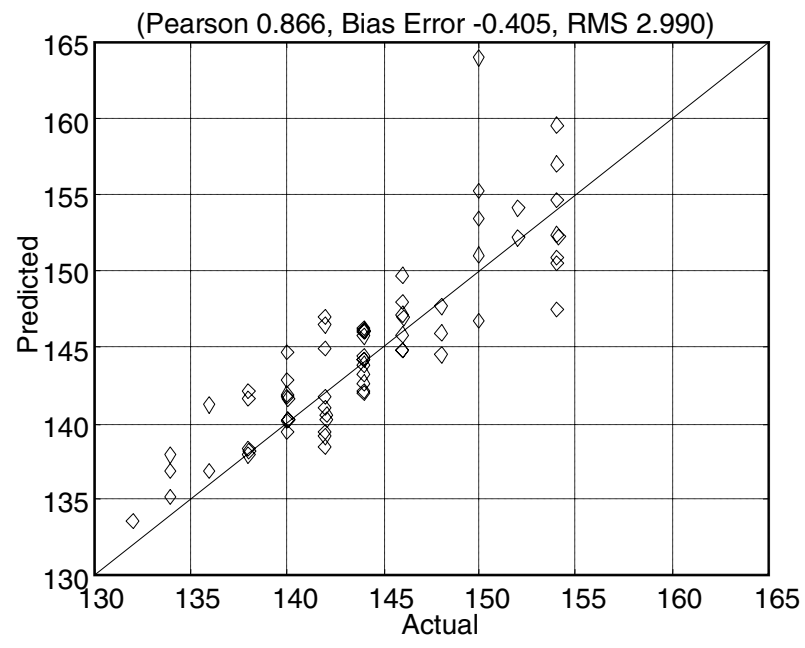

Figure 23 - Peak Pressure Position

Again, the area under the pressure curve, is a good estimation with less than $3.5 \%$ RMS and less than $-0.2 \%$ Bias errors, as shown in Figure 24.

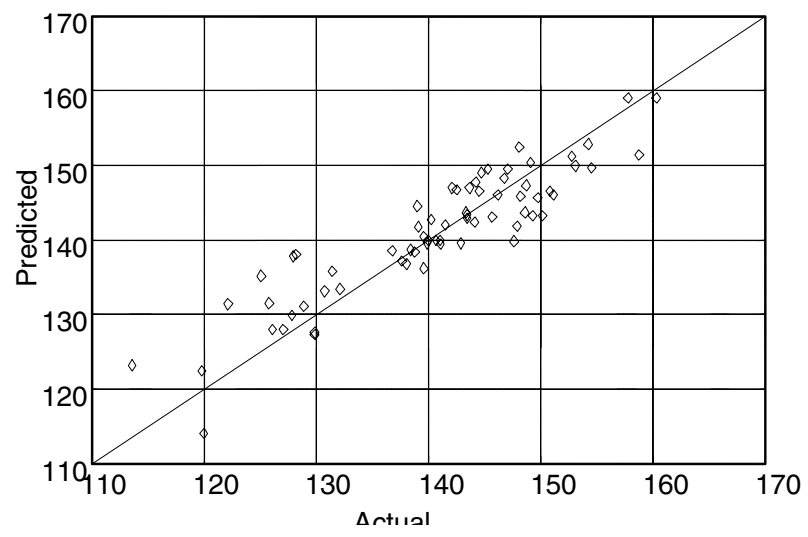

Figure 24 - Area Under the Pressure Curve

Figure 25 demonstrates the effect of using less training cycles on the quality of the reconstructed pressure trace. Here, only 7 of the previous design files (less than 500 design cycles) were supplied, and information about the engine operating conditions were not supplied to the ADALINE. The hold out data set used for testing was the same as for the previous tests.

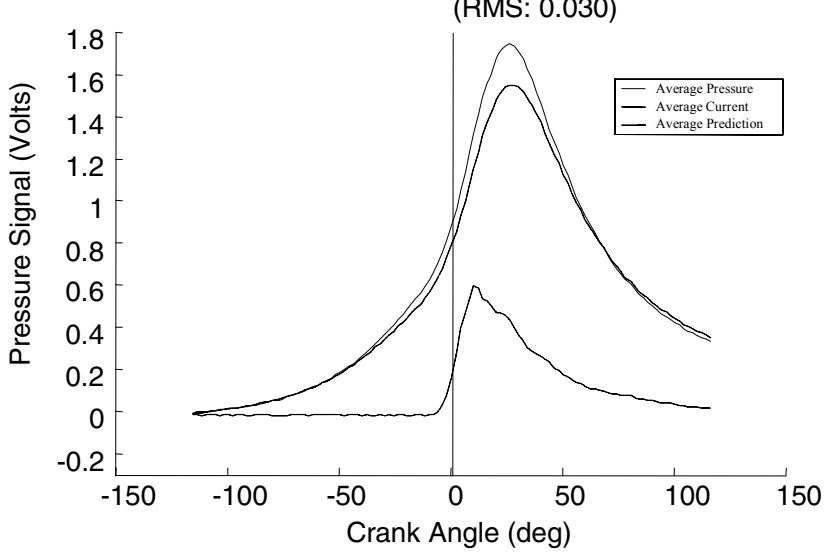

Figure 25 - The average predicted and actual pressures, along with the average ion-current

In this case, the pressure magnitude estimation RMS error rose to $8.2 \%$, an increase of about $4 \%$ over the previous results. The Bias error changed sign, but is still under $2 \%$. The position of peak pressure estimation was within $4 \mathrm{CA}$, an increase of around 0.6 degrees uncertainty, while the bias error remained under $-0.5 \% \mathrm{CA}$ degrees.

Compared to the previous results, the area under the curve prediction accuracy fell to a worst case scenario of less than 5\% RMS and less than 1.5\% Bias errors. Reasonable results were obtained for all predictions, in spite the fact that the only information supplied to the ADALINE was the ion-current signal. In addition, the net only "saw" 500 combustion events that where logged under different operating conditions to the test file. Similar prediction accuracies were noted under all engine operating condition sweeps, including ignition timing, air fuel ratio, and load/rpm, as long as the design files are selected so that the test file lies within the sweep's boundaries, thus demonstrating the suitability of using the ion-current signal when combined with a computationally inexpensive ANN for gathering in cylinder pressure data.

\section{DISCUSSION}

Misfire detection through ion-current measurement is a robust and reliable method under all operating conditions, even on a multi cylinder engine because under misfire conditions there is no ion-current signal. If the ion-current signal were to be incorporated into a closed loop control system, misfire judgment could be made by the time the piston is at TDC allowing the spark to be re-fired and some of the chemical energy in the charge could be recovered, and more importantly, burning the mixture before it reaches the catalyst, (although this strategy is unfeasible on standard ignition systems as the coil cannot be recharged in time). When an ion-current sensor that is separate to the spark plug is used, misfire caused due to electrode tip deposits can also be detected.

Pre-ignition detection is also possible, if an ion-current signal is sensed earlier than it is expected, for example 
because the mixture ignited due to hot surfaces in the chamber. Under some conditions, a very mild pre-ignition may occur that may not be detected due to the time taken for the flame to travel to the remote sensor. For this to be confused with normal combustion, it would have to occur very shortly before normal combustion, so this is not a serious drawback to the use of remote sensors.

The results indicate that there are some linear relationships between the pressure and ion signals characteristics. An analytical approach might not yield enough accuracy to resolve the feedback problem, but with the help of ANNs the precision of the predicted values, as indicated by the error's RMS and the Pearson coefficient, becomes impressive. In real world terms, if the engine parameters are known a PPP prediction should fall within $3.5^{\circ}$ C.A. Also, the pressure magnitude prediction should be within $10 \%$. All OBDII vehicles are equipped with the sensors needed to inform the neural network about the engine operating conditions, but even if these are not known, the PPP prediction uncertainty only increases to $4^{\circ}$ C.A. and the pressure magnitude to $11 \%$ total errors. These results were attained on a cycle-to-cycle prediction, with a sampling frequency of 1 sample $/ 2^{\circ}$ C.A., and without averaging nor information about important engine parameters such as coolant temperature, mass air flow, manifold absolute pressure etc and with relatively few "design" cycles. (Upwards of 50,000 cycles are normally used) $[7,20,21]$. Keeping in mind, that with a linear speed versus load table interpolation model, like the ones generally used in production vehicles today, the RMS error for PPP estimation is 3.3 C.A. degrees and the Bias error 1 C.A. degrees [8] the ANN performed adequately.

A further advantage is that table interpolation model performance drops considerably with ageing, whereas the ion-current in-cylinder sensor will contain ageing information. This is because the ion-current signal will decrease as the engine ages and cylinder compression decreases. Although no ageing test was performed, this effect was simulated by varying compression ratio and the results obtained promise good ageing behavior.

Similar issues like fuel additive effects and carbon contamination of the sensor were not examined. However, other studies [24] have shown that fuel additives affect mainly the amplitude and not the shape of the ion signal curve. As such, it was reported that they can be overcome through data normalization. Soot contamination, although not a major problem in gasoline engines, could be resolved through techniques like auto-calibration by measuring the resistance of the ion sensor prior to combustion [25].

Good estimation capabilities under varying compression ratio were also shown. Altering the compression influences the flame propagation speed. This can be measured with a remote spark plug ion sensor. The main use of this type of information is likely to be for correction of load table interpolation models as the engine ages. However, further research is required to establish why the ion-current signal decreased above $75 \%$ load.

The effect of changing air-fuel ratio was also investigated. It was shown, that in agreement with other researchers observations, the slope of the first spike of the ion-current is indicative of mixture strength. Although the possibility of completely substituting the oxygen sensor is arguable, it is clear that ion-current signals can be used for cylinder balancing. It is known that cylinders on a multi cylinder engine can have an AFR difference of $7 \%$ between them, with the oxygen sensor registering a stoichiometric value. If the ion-current signal can be used to balance cylinder $\mathrm{AFR}$, the overall emissions will drop, the temperature variance between cylinders will also drop and the output torque of each cylinder will equalize improving engine refinement.

The most commonly used technique for rapid catalyst warm-up is to retard the ignition at start-up. Manufacturing tolerances, equate to differences of AFR, dwell time and airflow between the cylinders and dictate a conservative maximum retard that will not sacrifice drivability, for the worst-case scenario. lon-current sensing will enable the maximum retard to be used, under all conditions.

With regards to the use of the additional ion-current sensors, it is noteworthy that since the measuring plug(s) was some distance away from the firing plug, a direct and firm relationship under all conditions of flame propagation speed and the start of the ion-current measurements was recorded. This is a unique characteristic of this investigation that proved worthwhile. When measuring from the firing plug, since the first peak is a result of the flame kernel created by the plug, it does not carry any valuable information. Only the second peak is dependent on the pressure and temperature. The problem with this is that under low load conditions this second peak disappears, since there is not enough pressure in the cylinder to cause post-flame ionization. This was, also, observed in our investigation, but had no effect on the results.

The difference in results between one and two sensor usage is small, but more measuring points result in higher accuracy. Sensors are mostly affected by local events, and an averaging strategy through the use of multiple sensors improves the quality of the data.

\section{CONCLUSIONS}

In this research, the potential of the ion-current measurement as feedback for engine control has been assessed. Data was collected using a single, and the two remote ion-current sensors, and it was found that whilst the use of a remote sensor remote sensor provides better insight than a single spark plug sensor, the is little benefit in using two remote sensors other than increased signal strength leading to a slightly wider diagnostic window. 
The single and double remote sensors were tested under different engine operating conditions to obtain an insight into the behavior of the ion-current signal when misfire occurs, air-fuel ratio changes, ignition timing is advanced, and compression ratio is changed. The ion-current signal was measurable under all tested conditions. Even in cycles where data was noisy or incomplete, the ANN method was still able to predict pressure measurants with adequate accuracy.

Detection of misfire has been shown to be possible through trivial methods. The ANN has also allowed for more complicated analysis adequate accuracy, such as AFR.

Also the predictive abilities of adaptive linear network designs that take the ion sensor's output as input and calculate PPP, pressure magnitudes, the area under the pressure curve, the width of the curve and also reconstruct the whole pressure signal were compared. The results prove that there is great potential for the use of ANN with ion-current signals in closed loop control.

The practical implementation in production vehicles still posses a few challenges. The provision of superior computational power in engine management systems being one of them, and the additional cost and complexity of using even a single remote sensor is also an issue.

\section{REFERENCES}

1. Kiencke $U$, Nielsen L, Automotive Control Systems, 2000, SAE International

2. Hellring $M$, Holmberg $U$, An lon-current Based Peak-Finding Algorithm for Pressure Peak Position Estimation, 2000-01-2829, SAE Technical Paper Series

3. Daniels C F, The Comparison of Mass Fraction Burned Obtained from the Cylinder Pressure Signal and Spark Plug Ion Signal, 980140, SAE Technical Paper Series

4. Saitzkoff A, Reinmann R, Mauss F, Glavmo M, InCylinder Pressure Measurements Using the Spark Plug as an Ionization Sensor, 970857, SAE Technical Paper Series

5. Hellring $M$, Holmberg $U, A$ Comparison of loncurrent Based Algorithms for Peak Pressure Position Control, 2001-01-1920, SAE Technical Paper Series

6. Hellring $\mathrm{M}$, Munther $\mathrm{T}$, Rognvaldsson $\mathrm{T}$, Wickstrom N, Carlsson C, Larsson M, Nytomt J, Spark Advance Control Using the lon-current and Neural Soft Sensors, 1999-01-1162, SAE Technical Paper Series

7. Hellring M, Rognvaldsson, Wickstrom N, Larsson $\mathrm{M}$, Ion-current based Pressure Peak Detection Under Different Air Humidity Conditions, 2000, Technical
Paper, Advanced Microsystems for Automotive Applications (AMAA)

8. Nielsen L, Ericsson L, An lon-Sense Engine-FineTuner, Vehicular Systems, Department of Electrical Engineering, IEEE Control Systems Magazine, Vol. 18, no.8, Oct 1998.

9. Eriksson L, Nielsen L, Glavenius M, Closed Loop Ignition Control by Ionization-current Interpretation, 970854, SAE Technical Paper Series

10. J. Auzins, H. Johansson and J. Nytomt "Ion - Gap Sense in misfire detection, knock and engine control"1995, SAE 950004

11. J. Forster, A. Gunther, M. Ketterer and K.J. Wald "Ion-current sensing for spark ignition engines" 1999, SAE 1999-01-2004

12. Y. Ohashi, M. Koiwa, K. Okammura and A. Ueda, "The application of ionic current detection system for the combustion control" 1999 SAE 1999-01-0550

13. L. Peron, A. Charlet, P.Higelin, B.Moreau, and J.F. Burq "Limitations of Ionization-current Sensors and Comparison with Cylinder Pressure Sensors"2000 SAE 2000-01-283.

14. Hellring $M$, Munther $T$, Rognvaldsson $T$, Wickstrom N, Carlsson C, Larsson M, Nytomt J, 'Robust AFR Estimation Using the lon-current and Neural Networks, 1999, SAE 1999-01-1161

15. Heywood J B, Internal Combustion Engine Fundamentals, 1988, McGraw Hill International

16. . Hellring, M., Rognvaldsson, T. and Wickstrom N. (2000). Ion-current Based Pressure Preak Detection Under Different Air Humidity Conditions. Advanced Microsystems for Automotive Applications 2000, pp.125-138

17. Hellring, M., Munther, Rognvaldsson, T. and Wickstrom N. (1999). Spark Advance Control using the Ion-current and Neural Soft Sensors. SAE Technical Paper 991162. Society of Automotive Engineers.

18. Hellring, M., Holmberg, U., An lon-current Based Peak-Finding Algorithm for Pressure Peak Position Estimation, (1998) Society of Automotive Engineers.

19. Byttner S, Rognvaldsson $\mathrm{T}$, Wickstrom $\mathrm{N}$, Strategies for Handling the Fuel Additive Problem in Neural Network Based lon-current Interpretation, 200101-0560, SAE Technical Paper Series

20. Hellring $M$, Munther $T$, Rognvaldsson $T$, Wickstrom N, Carlsson C, Larsson m, Nytomt J, Robust AFR Estimation Using the lon-current and Neural Networks, 1999-01-1161, SAE Technical Paper Series 
21. Daniels C F, The Comparison of Mass Fraction MIL - Malfunction Indicator Light Burned Obtained from the Cylinder Pressure Signal and Spark Plug Ion Signal, 980140, SAE Technical Paper Series

22. Nakajima $\mathrm{Y}$, Onoda $\mathrm{M}$, Nagai $\mathrm{T}$, Yoneda $\mathrm{K}$, Consideration for Evaluating Knock Intensity, JSAE Rev, Vol.9, 1982

23. Gazis A, Panosakis D, Chen R, Chen W-H, Computationally inexpensive Methods of lon-current Signal Manipulation for Predicting the Characteristics of Engine In-Cylinder Pressure

24. Malaczynski, G.W. and M.E. Baker, Real-Time Digital Signal Processing of lonization-Current for Engine Diagnostics and Control, SAE Technical Paper Series. 2003-01-1119:(2003).

25. Glavmo, M., P. Spadafora, and R. Bosch, Closed Loop Start of Combustion Control Utilizing Ionization Sensing in a Diesel Engine, SAE Technical Paper Series. 1999-01-0549:(1999)

26. Russ S., Peet G., Stockhausen W., Measurements of the Effect of In-Cylinder Motion on Flame Development and Cycle-to-Cycle Variations Using an Ionization Probe Head Gasket, SAE Technical Paper Series, (970507), 1997

\title{
ABBREVIATIONS
}

\author{
TDC - Top Dead Center \\ IVC - Inlet Valve Close \\ EVO - Exhaust Valve Open \\ CR - Compression Ratio \\ ITA - Ignition Timing Advance \\ AFR - Air Fuel Ratio \\ DAQ - Data Acquisition \\ MBT - Maximum Brake Torque \\ PPP - Peak Pressure Position \\ CA - Crank Angle \\ RMS - root mean square \\ OBD - On-board Diagnostics
}

